\title{
SPACE FOR THE FUTURE: EXHIBITING CHINA IN THE WORLD AT EXPO 2010.
}

\begin{abstract}
:
China's modernization and rise is commonly understood as a key factor that will shape future world order. This article examines narratives at Expo 2010 Shanghai China as an instance of the local constitution of this future world. Such imaginations of China and/in the world actively create the future, through assumptions about time and space that structure the possible imaginations of China, the World, and their interrelation.

This article examines how the technological and conceptual innovations that play out at the Expo draw on two common cosmologies, the 'unit-based' cosmology of the international state system and a Chinese 'holistic' imaginary of Tianxia (All-underHeaven). It shows how these two cosmologies order universal/particular, time/space and self/other through Beijing's 'harmonious world' policy. It argues that the two cosmologies are not mutually exclusive, but are deployed at the Expo in ways that reinforce one another by ordering spatial difference through teleological time. The effect is a story of China and the World where others are not different; they are just behind. This is a problem because the reduction of spatial difference to place in a historical queue makes it difficult to imagine plural futures, as opposed to The Future already inscribed in the story.
\end{abstract}

Keywords: Expo 2010 Shanghai China, world fair, harmony, harmonious world, the future, space.

Astrid Nordin

Politics, SoSS

University of Manchester

Oxford Road, Manchester, M13 9PL

United Kingdom

astrid.nordin@postgrad.manchester.ac.uk 
China's rise is commonly described in terms of inevitable destiny. Meanwhile, the PRC leadership is strictly managing the imagined form and significance of such a rise. Since 2008 China has used mega events to shape the expectations of domestic and international audiences, and thus to shape the future. Such mega events included the 2008 Olympic Games, the $200960^{\text {th }}$ anniversary of the founding of the PRC, and most recently Expo 2010 Shanghai China. The Expo took place from 1 May to 31 October 2010, and as usual when this type of thing is done in China it was the largest, most expensive, and most visited of its kind. ${ }^{1}$ The Expo was made possible by China's economic rise, but was also part of establishing the story of such a rise as true, and of narrating a future where China is no longer second in the world, but rises to be the benevolent leader of a new harmonious world order.

Under scrutiny here is this instance of world-making, or 'worlding.' By this term I mean that it shapes not only the imaginary of a particular state or nation, but of the world as a holistic unit. 'Worlding' takes Chinese experiences of the world seriously, while not assuming these to be transparent or innocent. ${ }^{2}$ The link between the future and time seems obvious. However, I want to begin by writing about space. This article builds on the idea that 'the dichotomy between, and the ethical imperatives of self and other, is often interpreted through a language of spatial containers.' ${ }^{3}$ Such division has become recognized as a vehicle for identity formation through its associations, because it is used to categorize that which is the same space, homogeneity and self, against that which is an other space, alterity and difference. ${ }^{4}$ In becoming imbued in this chain of meanings - as that which divides or unites, makes same or makes other - the way we think space becomes fundamental to what we think the relation between entities such as China and the World was, is and will be.

The following analysis begins by outlining two common imaginings of space that underpin the way scholars think about China's future in the world. Thereafter I argue that these imaginings are ethically problematic because they align spatial division in linear time. The effect is a story of China and the World where others are not different, they are just behind. I then show how these same spatial imaginaries are deployed at the Expo and how units in space become aligned in a time that runs towards a particular Future. In this story 'The Future' is one where China legitimately leads a new harmonious world order. 


\section{Two Dominant Cosmologies.}

Underpinning orderings of the world are specific imaginations of time and space. In the case of China in the world there are two common ones. The first is what I call 'unit-based space,' that of space as calculable bounded space, as containers of societies. The second is what has been referred to as a space 'with no outside' (无外), what I call here 'holistic space.'

Unit-based space.

The first kind of space comprises common western conceptualizations of nationstates, modernization and development. 'Cultures,' 'societies,' 'civilizations' and 'nations' are imagined as having an integral relation to bounded spaces, internally coherent and differentiated from each other by separation. 'Places' are seen as bounded, with their own internally generated authenticities, defined by their difference from other places that lay outside, beyond their borders. ${ }^{5}$ Chinese spatial units may vary from the PRC state, to Greater China, to Sinic Civilization, but the basic spatial imaginary, built on separate units, that underpins them is the same.

Holistic space.

The second kind of space, 'holistic space', has parallels with some extreme ideas of globalization as free unbounded space, where everything is always already networked and connected to everything else. ${ }^{6}$ It is, moreover, prominent in the Chinese concept of Tianxia, or 'All-under-heaven,' which has become increasingly popular with both a domestic and an international audience. It is developed at least partly in response to perceived problems in the Westphalian system, and aims to do away with them. The scholar who has most systematically relaunched this concept as a Chinese (and better) concept of world order is Zhao Tingyang. ${ }^{7}$ His claim is that Chinese thought does not operate through the self/other distinction of Western thought, that there is no dichotomized other in Tianxia, and hence 'no outside' (无外).

The two spatial imaginaries are commonly described as opposites in the literatures on China and the world, with one replacing the other. First, it is said, pre-modern China had a holistic view of space. This cosmology was replaced by a unit-based territorial imaginary when China had to transform into a modern (nation)state. Now, it is claimed again, the territorial notion of space is no longer plausible under 
globalization, ${ }^{8}$ and China is deterritorializing. Following William A. Callahan's work on maps of National Humiliation ${ }^{9}$ this article challenges such notions through arguing that both these spatial imaginaries are working simultaneously in contemporary China, and that they rely on each other.

The problem with the two cosmologies.

My argument is that although they are portrayed as opposites, the most common ways of speaking of China in the world are problematic in precisely the same way: they align spatial difference in a temporal sequence, a move which prevents the conceptualization of the other as equal, or coeval. I am not the first to point out this problematic move of unit-based literatures. As explained by Doreen Massey and by Johannes Fabian, the basic manoeuvre goes like this. Space is divided into bounded units, with an inside distinct from its outside. Subsequently, the classifying units of space are conceived of in terms of temporal sequence. Discourses of modernization, development and civilizing missions all perform this same manoeuvre. Euphemistically renaming the uncivilized as 'developing' does nothing to change the basic move: others are not simply different, they are just behind. Their future is our past. Eventually, they will become like us. ${ }^{10}$

But what about alternative accounts, such as Tianxia? Throughout his reformulation of Tianxia, Zhao Tingyang takes the term to sometimes mean 'the World,' sometimes 'Empire,' but always as a political cosmology which explicitly tries to break with the problematic self-other relations of discourses of modernity in general and the nationstate system in particular. ${ }^{11}$ The problem emerges when Zhao, as a result of his prioritization of order, comes to insist on the homogeneity of his all-inclusive space, where 'all political levels ... should be essentially homogenous or homological so as to create a harmonious system.'12 Clearly, for such homogeneity to be born from a heterogeneous world, someone must change. Zhao argues that 'one of the principles of Chinese political philosophy is said "to turn the enemy into a friend" ... in a word, to "transform" the bad into the good.'13

Callahan $^{14}$ and Barabantseva ${ }^{15}$ point out the potentially oppressive attitude that emanates from the prioritization of order in this reading of Tianxia. From the above it is similarly clear that even without the stark spatial dichotomization, there is no space 
for others to follow their own paths. 'The bad' will be transformed into 'the good,' the other turned into self. Their future is predefined for them. Their future is not open.

\section{The Cosmologies at the Expo.}

Figure 1: Map from online Expo. ${ }^{16}$

Unit-based cosmology at the Expo.

Unit-based spatial imaginaries are immediately obvious at the Expo. Space at the Expo is typically imagined in a modernist manner as a flat surface upon which humans act, as a 'stage' or 'platform.' As for the unit-based territorialization of this surface, there are many layers of simulation and representation of such a jigsawpuzzled world. The Expo site is organized as an imagined Westphalian world, divided into bounded continents of national pavilions. ${ }^{17}$ At the online Expo, we can take guided tours of pavilions and exhibitions and get a virtual passport in which we can collect visa stamps from the various territories visited.

Likewise, at the Expo visitors, who may never have been abroad and may not own a passport in the outside world, can get a multitude of visa stamps and 'play' at being well-travelled. It is an enactment of the world that pretends such international life is readily available and unrestricted. It draws up borders and barriers in order to let them be crossed, but by no means erased or blurred. Through turning visa collection into a game, border controls appear innocent at the same time as their indisputable 'natural existence' between states is reinforced. However, it becomes clear that partaking in this game of 'open borders' is conditional. I met a young travel guide, who visited the Expo with 60 tourists from Beijing. While her group went into the Pavilion of Future (subtitled 'Dream inspires the future') and had their pretend passports stamped, she waited ticketless outside, stopped at the border because she did not have the right papers. Simultaneously, the 'external' nation-state system echoed in citizenship regimes inside the Expo when producing a 'real' passport meant one could jump pavilion queues for the pavilion of the country that had issued it.

This way of conceiving of space in terms of bordered units is marked throughout the Expo. China's own pavilion of regions is no exception, sub-divided into regional containers of culture - many even look like boxes with essentialized culture exhibited inside, like the virtual version of the Tibetan pavilion below. 
Figure 2: 'Tibet in the heaven. ${ }^{18}$

Holistic cosmology at the Expo.

Although obviously steeped in a unit-based spatial imaginary, these bounded units are also enveloped in the holistic celestial order of one-worldness. The key terms in holistic imaginaries are the 'all-encompassing' or 'all-inclusive,' that with 'no outside' or 'no exception,' 'network,' and of course 'Tianxia.'

The holistic imagination of everything as always already connected to everything else appears in the room in Urbanian Pavilion themed 'Connection' (交往). This room is based on the 'scientific theory called six degrees spatial theory,' which states that no two people are separated by more than 6 relationships. ${ }^{19}$ On the ceiling is projected a film showing selected people's movements on a map. Portraits of people appear in circles connected by lines to more and more other people/circles until they form a web or network on the round screen, bringing your mind to the Earth and thus the idea that all people of the world are connected. ${ }^{20}$ There is no one outside the network. Moreover, this claim is backed up by science, and thus requires no further explanation.

The Pavilion of City Being describes the city as a living being or organism, focusing on the theme of 生命, meaning life, being or bios. The holistic imagination implied in this idea of the city as one body or life is clear from slogans such as 'city being multiplies endlessly, held together by superseding cycles' and 'the unceasing adjustment between people and city maintains city life harmonious, healthy city life requires our common protection. ${ }^{21}$

The Pavilion of Urban Planet moreover draws on a holistic spatial imaginary to tell us on the 'Road of Solutions' how the resolution to the world's problems can be found: 'The seasons change, settlement becomes cities and trading routes develop into a completely networked world ... Only with open mind and all-inclusive view can we bring the hope of sustainable growth to our planet Earth [emphasis added].'

These references to the organically connected single organism or body, the web of connections with no outside and the completely networked world with an all inclusive view all provide the basis of a holistic spatial imaginary. Moreover, the comments above indicate that this holistic imaginary is taken to demand the 
harmonious balance of all and 'our common protection,' notions that will be further explored below.

\section{Classification in time and space.}

From the above we see that worlding at the Expo draws on both unit-based and holistic notions of space. This instance shows the two spatial imaginaries coexisting in contemporary China, and so refutes the idea that one would be superseding the other. I next look closer at how they work in tandem at the Expo.

Classifying space.

Throughout the Expo, classification of space is marked. We have seen it above in the unit-based form of mapping state units, as well as that of regions as containers of culture. The holistic Tianxia concept does not refer to the jigsaw-puzzled space of the unit-based imaginary, but nonetheless classifies and sequentializes through a centre/periphery divide. Tianxia ordering is similar to the Expo site centred on the Chinese pavilion designed to represent ancient Chinese culture - its 'forbidden city red' beams bringing to mind Beijing's centralized power.

Similarly, the comparison and contrasting of 'East' and 'West' is ever present. In a film screened at the Pavilion of City Being we are watched from the screen by 'the eyes of Eastern people, the eyes of Western people. ${ }^{22}$ Likewise, 'Pre-show Hall' in the Pavilion of Footprint shows 'ideal cities' as they have been imagined in the East and in the West. Dreaming of a better future is described as universal, or eternal (永恒), but similarities end there and juxtaposition takes over.

Aligning space in temporal sequence.

The division of space into civilizational/regional/national units is aligned with division of time into eras, often in its ancient/modern guise. This is where, just as in academic discourse, we see evidence of the alignment of juxtaposed here/there, modern/ancient and subject/object. ${ }^{23}$ As a number of 'developing' countries could not fund their own participation in Expo 2010, Chinese subsidies to these countries ensured there were more state and organization pavilions, 246, than at any previous Expo. $^{24}$ The vastly different budgets and scales meant pavilions gave the impression of a developmental or aspirational classification, in a visual display of global inequality. As in global development, China financially supported 'less-developed' 
states in a way that visually emphasized the impressive scale and central location of the Chinese pavilion and reaffirmed China as a 'helper' and 'developer' ahead of the 'helped' and 'developing' states at the Expo site periphery, such as the African Joint and Pacific Joint pavillions.

This convening of others differentiated in space through time is crystallized in Urbanian Pavilion, which shows the morning rituals of families taken to represent five continents. It shows the similarities of getting up, washing, brushing teeth and so on of people from these different spatial/cultural units. However, the sequentialization in time is obvious. The man from Rotterdam has an electric toothbrush and the Chinese middleclass office worker wears new pyjamas in his modern bathroom, whereas the bathroom in Rio de Janeiro looks worn and dirty. In this way spatial difference is aligned in temporal sequence. We all do the same thing; it is just that some are a bit behind.

Time running towards a goal.

Spatial division is thus not only conceived as classification of space, but also as classification in time. This classification is moreover conceived of in a time that runs towards a particular end. Clock time running out or towards the future is emphasized at the Shanghai train station's Expo clock tower, as well as throughout the Expo itself by feature clocks, ticking pendula and hourglasses.

The intertwining of temporal notions with strong assertions as to what Chinese identity is in world affairs is clear from an introduction to the Expo on its official website:

With a long civilisation, China favours international exchange and loves world peace. China owes its successful bid for the World Exposition in 2010 to the international community's support for and confidence in its reform and opening-up. The Exposition will be the first registered World Exposition in a developing country, which gives expression to the expectations the world's people place on China's future development ... We count on the continuing attention, support and participation of all the peace-loving countries. ${ }^{25}$

In this context, depicting China as original confers on it a status as fore-runner of developing countries, conveniently forgetting the 1949 Haiti Expo. ${ }^{26}$

China's present and future direction is frequently depicted in terms of a return to an original or always intended state. ${ }^{27}$ The Expo itself is typically portrayed as the 
fulfilment (lead by the PRC/CCP party-state) of an ancient Chinese dream. This portrayal appears in articles, ${ }^{28}$ in books such as 100 years of Expo dream, ${ }^{29}$ and in the World Expo Museum that looks back at more than 150 years of historical preparation for the Shanghai Expo. Online commentators echo such narratives, and one commentator on the Expo online 'Dream Wall' comments that 'I believe in China's actual strength, a country that has 5000 years of civilization must be able to produce glory once more. ${ }^{30}$

The concluding chapter of a book on Expo etiquette, aimed at Chinese readers, clearly conceives of politeness in terms of the return to an original state. We are encouraged to 'utilize the Shanghai Expo as a historical turning point, to make every one of us change into politely speaking Expo people' and after being told about 'the Expo's demand on the etiquette of the people of the host country' to 'through the Expo make elegant etiquette return to China. ${ }^{31}$

Finally, the feature film of the Xinjiang regional pavilion demonstrates how classification of time and space come together into a particular, goal-oriented progress under PRC leadership:

[Xinjiang is] the communication land of four great civilisations of the world ... It once was the road of bonze Xuanzang, the silk road, the road of western expedition and the road of eastern return ... The great transformation of 60 years is the evidence of our diligence and intelligence ... Today, the assistance from the motherland also lights up the passion in Xinjiang. ${ }^{32}$

This quote brings together the numerous elements that make possible the problematic imagination of self-other relations that is under discussion in this article. A separation between civilizations is posited. Xinjiang is subsequently conceived of as a place where these separate civilizations meet. Progress is imagined as a return to a state that once was, and that is now returning through Chinese diligence in its (re)civilizing mission. One can only wonder at the irony as the motherland's assistance 'lights up the passion' in Xinjiang after the brutal ethnic clashes in the years running up to the Expo. $^{33}$

Metaphors of lines, circles, spirals and pendula may be used to describe this temporality, but may be misleading as they change significance in their combined use. ${ }^{34}$ Analogue clock time, for instance, may be circular if used as for example a toy, but indicates linear time flow when allied with other concepts, such as civilizational 
progress and development. The point of China's progress/return (to its rightful place as world leader) is not whether we describe it using the metaphor of the circle or the line. Of key importance is instead the way it operates through a classification of time and space and there is no doubt as to where we are/should be heading. The point is that these temporalities support each other and lead towards the same ultimate endpoint.

\section{The Future Is One Where China Leads a New Harmonious World Order.}

Chinese discussions surrounding the Expo typically conferred on it one central meaning - it was a sign of China's legitimate rise to world leadership. Wishes for Chinese superiority similarly appeared in the online Vanke Pavilion, the corporate pavilion for a large Chinese property developer. One commentator wished that in 2049 'China is in leading position in the world' (中国处于世界领先) and another exclaimed that by then 'China has really changed into a great cultural country, ten thousand countries come to pay tribute!' (万邦来朝). ${ }^{35} \mathrm{~A}$ majority of participants in the Expo's 'Dream wall' expressed love for the motherland, the Expo and Shanghai, with one exclaiming, 'Go Expo, China is invincible!' (中国无敌). ${ }^{36}$

China's harmonious world at the Expo.

Key to justifying this Chinese world leadership is depicting such a world as 'harmonious' (和谐), in accordance with Chinese President Hu Jintao's 'harmonious world' discourse. ${ }^{37}$ The Expo is steeped in this language of harmony. China's national pavilion begins with the film 'Harmonious China' (和谐中国) and concludes with telling us 'the lotus flowers blossom, symbolizing the harmonious and glorious future of Chinese cities. ${ }^{38}$ The Xinjiang pavilion is labeled 'Xinjiang - a harmonious land'. We go to the Expo on a harmonious train, to visit Harmony Tower, and if we hurt ourselves we can have a band-aid from the harmonious first aid kit.

Figure 3: Harmonious first aid kit.

The language of harmony is also prevalent among the wishes of Vanke Pavilion. One participant wishes:

2010: A life at ease A peaceful and stable job Wishing the great motherland is increasingly thriving and prosperous My family is increasingly harmonious and happy 
2049: There is no war in any corner of the world There is no discrimination Peaceful getting along and also wish that when we reach that time people from every corner of the world can all profoundly understand China. ${ }^{39}$

We see here a mixing of ideas of harmony with notions of a good personal life, a thriving China, and an image of peacefully connected world citizens who understand China. A blurb for Pavilion of Future's harmony sculpture similarly personalizes world harmony: 'Core concept of traditional Chinese culture: Only the harmony of the world and all things constitute the harmony of human's spirit.' Just as in Zhao's Tianxia, we require the harmony of all things. There can be no outside to the system, or it will fail. All things must be incorporated. This, the claim is, is a distinctly Chinese idea of world order.

The two cosmologies and harmony.

Throughout all of these imaginings of China in the (harmonious) world, the two spatial imaginaries combine in ways that repeat the problems outlined above with regards to academic discourse, making difficult the imagination of the other as coeval. The unit-based spatial imaginary provides a condition of possibility of Chinese particularism. Throughout the Chinese pavilions at the Expo, China is the very origin of civilization and of the world - it is where the first fire burnt, the first bird flew, and the superior values of Confucian harmony originated. The holistic spatial imaginary becomes key to imagining the need for spreading this civilization, and for the Chinese civilizing mission we currently observe around the world. ${ }^{40}$ The holistic idea of space is core to construing the rise of China to leadership of a harmonious world as peaceful and beneficial to all. In actuality, there is no outside, everything is always already connected to everything else, and the view of the Chinese party elite is a 'view from nowhere,' or a view 'from the world.'

Reinforcing the notion of China's harmonious world.

Many of these themes are echoed through non-Chinese pavilions at the Expo, including the two spatial imaginaries, the goal-oriented notion of time, East-West juxtaposition and a reliance on blurry notions of civilization. Notably, many foreign actors used the Expo to exhibit their willingness to buy into the Chinese discourse on harmonious world, allowing it prominence of place in the way they name, speak of and write of their own pavilions. 'Harmony' in particular is given legitimacy through frequent use in foreign pavilions, such as 'Harmonious relations' (Pacific joint 
pavilion), 'Feel the harmony' (Austria), 'Harmony of the heart, harmony of the skills' (Japan), and so on. While popular academic analyses of Chinese foreign policy argue that the PRC is being 'socialized' into values and norms of 'international society', ${ }^{41}$ the Expo showed the opposite: 'outsiders' competing to be most attentive to and accommodating of China's purported self-image.

Non-Chinese corporate pavilions too helped reinforce and legitimate this particular version of 'harmony' with reference to Chinese history. One example was the pavilion called 'Tianxia yi jia' (天下一家): 'Tianxia one family', officially translated as 'We are the World.' This pavilion was German multinational Siemens's corporate pavilion, showcasing its technology through the aspirational middle class future of interactive games and wine coolers that will apparently be available to Chinese people in 2015. Entering Siemens's harmonious and commercialized rendition of Tianxia we are photographed. As in a miracle of scientific development our faces appear on a film screen at the exit, manipulated to sing together in harmony with the Expo theme tune:

After scanning and capturing the user's facial features, the image will be recorded and transformed into an avatar allowing users to feel as if they are starring in a pre-programmed movie or video ... How will this technology better our lives? Provides an entertaining experience for people to play a role in a movie or become a "star". Everyone has the chance to stand in the spotlight.

China's Future, in this commercialized version as in its official one, provides the Time and Space for us all to be stars in the spotlight. It is worth recalling here the organizers' own reading where the Expo took place because of 'the international community's support for and confidence in [China's] reform and opening-up,' expressing 'the expectations the world's people place on China's future development' with China sternly counting on 'the continuing attention, support and participation of all the peace-loving countries. ${ }^{42}$ Foreign investment in the Expo is commonly rendered by Chinese media as an endorsement of the Chinese model for its rise, and is taken as a showcase for how harmonious the world is under Chinese leadership. In this version of the Future World we are allowed into the spotlight on the condition that we become avatars that sing simultaneously in one voice to the Chinese melody.

\section{Chinas' Futures and the Worlds' Futures}


This article has traced two common ways of imagining China's relation to the world, what I have called unit-based and holistic cosmologies. Both these spatial imaginaries are prominent in Expo worlding, aligning classified units of time/space in sequence. What we see happening on the ground in China refutes imaginings of the two cosmologies as mutually exclusive with one replacing the other. They are simultaneously deployed in contemporary China, in ways that support a particular discourse on China and the World, prescriptive of a particular future where China leads a new harmonious world order.

World fairs were from the outset an exercise where self/other relations were heavily tinted by imperialism. ${ }^{43}$ Today, although the specific selves and others reproduced by the Expo may be somewhat different their fundamental manoeuvre is the same. The articulation of time/space with the narrative of harmony is problematic because it marginalizes concepts of equality and difference. Others are not properly different, they are just behind. Just like Zhao's Tianxia, the Expo worldview portrays itself as 'from the world' or 'from everywhere,' yet insists on 'specifically Chinese' terms and experience. This is reinforced as the Expo shows an already nationalistic domestic audience a China that rightfully rises to the place of world leader and the folly of anyone imagining that such a rise would be less than beneficial to all. This is buttressed by readings of foreign involvement and investment in the Expo as endorsements of the Chinese model for its rise, and is taken as a showcase for how harmonious the world is under Chinese leadership.

The Expo worldview portrays itself as 'from the world,' yet insists on the singular China's Future as the (Harmonious) World's Future. On this view, there is only one Future, and it does not welcome contestation. Nonetheless, contestation does take place, which is the subject of Callahan's contribution to this special issue. ${ }^{44}$ I similarly propose that we can refuse scripting our songs in the pre-programmed manner suggested by predominant imaginings at the Expo. It can indeed be possible to step up to the challenge of coeval multiplicities that time and space should present us with. Through displacing slightly the apostrophes of 'China's futures and the World's futures' we come to think not only of multiple futures, but also of both Chinas and Worlds in the plural: of 'Chinas' futures and the Worlds' futures'. Building such pluralistic imaginings of China in the world remains a task for future research. 
References

Agnew, John (1998) Geopolitics: Re-visioning world politics. London: Routledge.

Ashley, Richard K. (1987) The Geopolitics of Geopolitical Space: Toward a Critical Social Theory of International Politics. Alternatives 12: 403-34.

Barabantseva, Elena (2009) Change vs. Order: Shijie Meets Tianxia in China's Interactions with the World. Alternatives: Global, Local, Political 34: 129-55.

Bureau International des Expositions (2011) Port au Prince 1949. http://www.bieparis.org/site/en/component/docman/cat_view/100-expodocuments.html?start $=30$, accessed 20 January.

Callahan, William A. (2009) The Cartography of National Humiliation and the Emergence of China's Geobody. Public Culture 21(1): 141-73.

Callahan, William A. (2010) China: The pessoptimist nation. Oxford: Oxford University Press.

Callahan, William A. (2012) Shanghai’s alternative futures: The World Expo, citizen intellectuals and China's new civil society. China Information 26(2).

Campbell, David (1998) Writing Security: United States Foreign policy and the Politics of Identity. Manchester: Manchester University Press.

Crang, Mike, and Thrift, Nigel (2000) Thinking Space. London: Routledge.

Expo 2010 Shanghai China (2006) 1949 Port au Prince - Haiti. http://en.expo2010.cn/a/20080614/000094.htm, accessed 20 January 2011.

Expo 2010 Shanghai China (2006) New research reveals China took part in first World Expo.

http:/en.expo2010.cn/expo/expo_english/oe/awe/cwe/userobject1ai35918.ht $\mathrm{ml}$, accessed 20 January 2011.

Expo 2010 Shanghai China (2008) Brief Introduction of World Expo Shanghai (2008). http://en.expo2010.cn/a/20081116/000004.htm, accessed 15 September 2010

Expo Shanghai Online (2010) China pavilion. http://pavilion.expo.cn/z0001/ssize/explainchinavenue/index.html, accessed 18 September 2010 .

Expo Shanghai Online (2010) My Expo dream home. http:/en.expo.cn/jnh/dreamwall/index.html, accessed 18 September 2010.

Expo Shanghai Online (2010) Site tour. http://en.expo.cn/indexn.html, accessed 11 December 2010.

Expo Shanghai Online (2010) Tibet in the heaven. http:/pavilion.expo.cn/p6006/ssize/cn/index.html, accessed 11 December 2010.

Expo Shanghai Online (2010) Vanke pavilion. http//pavilion.expo.cn/e1016/ssize/index.html, accessed 19 September 2010.

Expo Shanghai Online (2010) Xinjiang pavilion. http://pavilion.expo.cn/p8006/ssize/index.html, accessed 19 September 2010.

Fabian, Johannes (1983) Time and the Other: how anthropology makes its object. New York: Columbia University Press.

Gell, Alfred (1992) The anthropology of time: cultural constructions of temporal maps and images. Oxford: Berg.

Johnston, Alistair I. (2008) Social States: China in International Institutions, 19802000. Princeton: Princeton University Press. 
Massey, Doreen (2005) For Space. London: Sage.

Nordin, Astrid (forthcoming) Taking Baudrillard to the fair: Exhibiting China in the World at Expo 2010. Alternatives: Global, Local, Political.

Nyiri, Pal (2006) The Yellow Man's Burden: Chinese Immigrants on a Civilizing Mission. The China Journal 56: 83-106.

Pettman, Jan (1996) Worlding women: a feminist international politics. London: Routledge.

Rydell, Robert W. (1984) All the World's a Fair: Visions of Empire at American International Expositions 1876-1916. Chicago: University of Chicago Press.

Shanghai shibohui shiwu xietiaoju (2009) Bai nian shibo meng (100 years of Expo dream ). Shanghai: Dongfang chuban zhongxin.

Tok, Sow Keat and Zheng Yongnian (2007) 'Harmonious society' and 'Harmonious world': China's policy discourse under Hu Jintao. University of Nottingham China Policy Institute Birefing Series, no. 26. Nottingham: University of Nottingham China Policy Institute.

Xinhua (2009) Thousands of Harmony Makers Sent to Urumqi Communities While Authorities Vow Harsh Punishment against Syringe Attackers, Xinhua, 6 September.

Xinhua (2010) Premier Wen declares Shanghai World Expo closed, Xinhua, 1 November.

Xinhua (2010) Shanghai World Expo wins worldwide applause, Xinhua, 31 October.

$\mathrm{Xu}$, Bo (2009) Shibo liyi (Expo Etiquette). Shanghai: Dongfang chuban zhongxin.

$\mathrm{Xu}$, Wei (2010) Zhutiguan quan jilu (Full record of theme pavilions ). Shanghai Shibo. Shanghai: SNP Leefung Printers. Special issue 1, 05 June.

Zhao, Tingyang (2005) Tianxia tixi : shijie zhidu zhexue taolun (Tianxia system: Philosophical discussion of World System). Nanjing Shi: Jiangsu jiao yu chu ban she.

Zhao, Tingyang (2006) Rethinking Empire from a Chinese Concept 'All-underHeaven' (Tianxia). Social Identities 12: 29-41.

Zhao, Tingyang (2009) Huai shijie yanjiu: zuo wei di yi zhexue de zhengzhi zhexue (Investigations of the bad world : political philosophy as first philosophy). Beijing: Zhongguo renmin daxue chubanshe.

Notes

I thank William A. Callahan, Maja Zehfuss, Andrew Slack, Chris Courtney and two anonymous referees for helpful comments on drafts of this article, and Linsay Cunningham-Cross for comments as well as help with photography and interviews during the fieldwork on which this article is based. I would also like to give thanks for constructive feedback to participants and discussant at the workshop China's Futures - and the World's Future, University of Manchester, 11 February 2011. I thank the Swedish Institute of International Affairs for providing a collegial environment in which final revisions to the article were made, and particularly to Björn Jerdén and Mikael Weissmann for helpful comments. Generous funding from the UK Economic and Social Research Council and British Inter-University China Centre made the research possible. The contents of the article remain the responsibility of the author.

\footnotetext{
${ }^{1}$ Xinhua. Premier Wen declares Shanghai World Expo closed, Xinhua, 1 November 2010.
} 
2 cf. Jan Pettman, Worlding women: a feminist international politics, London: Routledge, 1996, $\mathrm{x}$.

${ }^{3}$ Mike Crang and Nigel Thrift, Thinking Space, London: Routledge, 2000, 7.

${ }^{4}$ Richard K. Ashley, The Geopolitics of Geopolitical Space: Toward a Critical Social Theory of International Politics, Alternatives 12, 1987: 403-34.

${ }^{5}$ Ashley, Geopolitics; David Campbell, Writing Security: United States Foreign policy and the Politics of Identity, Manchester: Manchester University Press, 1998. ${ }^{6}$ Doreen Massey, For Space, London: Sage, 2005, 81.

${ }^{7}$ Zhao Tingyang, Tianxia tixi: shijie zhidu zhexue taolun (Tianxia system: Philosophical discussion of World System), Nanjing Shi: Jiangsu jiao yu chu ban she, 2005; Zhao Tingyang, Rethinking Empire from a Chinese Concept 'All-under-

Heaven' (Tianxia), Social Identities 12, 2006: 29-41; Zhao Tingyang, Huai shijie yanjiu: zuo wei di yi zhexue de zhengzhi zhexue (Investigations of the bad world : political philosophy as first philosophy) Beijing: Zhongguo renmin daxue chubanshe, 2009.

8 John Agnew, Geopolitics: Re-visioning world politics, London: Routledge, 1998.

${ }^{9}$ William A. Callahan, The Cartography of National Humiliation and the Emergence of China's Geobody, Public Culture 21(1), 2009: 141-73; William A. Callahan, China: The pessoptimist nation, Oxford: Oxford University Press, 2010.

${ }^{10}$ Massey, For Space; Johannes Fabian, Time and the Other: how anthropology makes its object, New York: Columbia University Press, 1983.

${ }^{11}$ Zhao, Rethinking Empire, 31.

12 Ibid, 33.

${ }^{13}$ Ibid, 34.

${ }^{14}$ Callahan, Pessoptimist nation, ch. 7.

${ }^{15}$ Elena Barabantseva, Change vs. Order: Shijie Meets Tianxia in China's

Interactions with the World, Alternatives: Global, Local, Political 34, 2009: 129-55.

${ }^{16}$ Expo Shanghai Online, Site tour, http://en.expo.cn/indexn.html, accessed 11 December 2010.

${ }^{17}$ Elsewhere I excavate this imaginary in more detail as a 'simulacrum' of world order, see Astrid Nordin, Taking Baudrillard to the fair:

Exhibiting China in the World at Expo 2010, Alternatives: Global, Local, Political, forthcoming.

${ }^{18}$ Expo Shanghai Online, Tibet in the heaven,

http://pavilion.expo.cn/p6006/ssize/cn/index.html, accessed 11 December 2010.

${ }^{19} \mathrm{Xu}$ Wei, Zhutiguan quan jilu (Full record of theme pavilions ), Shanghai Shibo, Shanghai: SNP Leefung Printers, Special issue 1, 05 June 2010, 27.

${ }^{20}$ Ibid, 27.

${ }^{21}$ Ibid, 40 .

${ }^{22}$ Ibid, 49

${ }^{23}$ Fabian, Time.

${ }^{24}$ Xinhua, Shanghai World Expo wins worldwide applause, Xinhua, 31 October 2010.

${ }^{25}$ Expo 2010 Shanghai China, Brief Introduction of World Expo Shanghai (2008), http://en.expo2010.cn/a/20081116/000004.htm, accessed 15 September 2010

${ }^{26}$ Expo 2010 Shanghai China, 1949 Port au Prince - Haiti (2006),

http://en.expo2010.cn/a/20080614/000094.htm, accessed 20 January 2011; Bureau

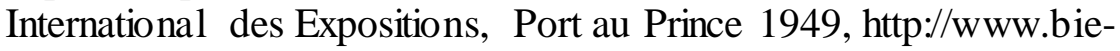


paris.org/site/en/component/docman/cat_view/100-expo-documents.html?start=30, accessed 20 January 2011.

${ }^{27}$ I discuss this logic of the return in more detail in Nordin, Taking Baudrillard to the Fair.

${ }^{28}$ Expo 2010 Shanghai China, New research reveals China took part in first World Expo (2006),

http:/en.expo2010.cn/expo/expo_english/oe/awe/cwe/userobject1ai35918.html, accessed 20 January 2011.

${ }^{29}$ Shanghai shibohui shiwu xietiaoju, Bai nian shibo meng (100 years of Expo dream), Shanghai: Dongfang chuban zhongxin, 2009.

${ }^{30}$ Expo Shanghai Online, My Expo dream home, http://en.expo.cn/jnh/dreamwall/index.html, accessed 18 September 2010.

${ }^{31}$ Xu Bo, Shibo liyi (Expo Etiquette), Shanghai: Dongfang chuban zhongxin, 2009, 141-6.

32 Expo Shanghai Online, Xinjiang pavilion, http://pavilion.expo.cn/p8006/ssize/index.html, accessed 19 September 2010.

${ }^{33}$ Xinhua, Thousands of Harmony Makers Sent to Urumqi Communities While Authorities Vow Harsh Punishment against Syringe Attackers, Xinhua, 6 September 2009.

34 cf. Alfred Gell, The anthropology of time: cultural constructions of temporal maps and images, Oxford: Berg, 1992.

${ }^{35}$ Expo Shanghai Online. Vanke pavilion, http://pavilion.expo.cn/e1016/ssize/index.html, accessed 19 September 2010.

${ }^{36}$ Expo Shanghai Online, Expo dream home.

${ }^{37}$ Sow Keat Tok and Zheng Yongnian, 'Harmonious society' and 'Harmonious world': China's policy discourse under Hu Jintao, University of Nottingham China Policy Institute Birefing Series, no. 26, Nottingham: University of Nottingham China Policy Institute, 2007.

${ }^{38}$ Expo Shanghai Online, China pavilion, http://pavilion.expo.cn/z0001/ssize/explainchinavenue/index.html, accessed 18 September 2010.

${ }^{39}$ Expo Shanghai Online, Vanke.

${ }^{40}$ Pal Nyiri, The Yellow Man's Burden: Chinese Immigrants on a Civilizing Mission, The China Journal 56, 2006: 83-106.

${ }^{41}$ For example, Alistair I. Johnston, Social States: China in International Institutions, 1980-2000, Princeton: Princeton University Press, 2008.

${ }^{42}$ Expo 2010 Shanghai China, Brief Introduction.

43 Robert W. Rydell, All the World's a Fair: Visions of Empire at American International Expositions 1876-1916, Chicago: University of Chicago Press, 1984. ${ }^{44}$ William A. Callahan, Shanghai's alternative futures: The World Expo, citizen intellectuals and China's new civil society, China Information, 26(2), 2012. 